\title{
Behavioral features in Prader-Willi syndrome (PWS): consensus paper from the International PWS Clinical Trial Consortium
}

\author{
Lauren Schwartz ${ }^{1,2^{*}}$ (D) Assumpta Caixàs ${ }^{3,4}$, Anastasia Dimitropoulos ${ }^{5}$, Elisabeth Dykens ${ }^{6}$, Jessica Duis ${ }^{7}$, \\ Stewart Einfeld ${ }^{8}$, Louise Gallagher ${ }^{9}$, Anthony Holland ${ }^{10}$, Lauren Rice ${ }^{11}$, Elizabeth Roof ${ }^{12}$, Parisa Salehi ${ }^{13}$, \\ Theresa Strong ${ }^{1,14}$, Bonnie Taylor ${ }^{15}$ and Kate Woodcock ${ }^{16}$
}

\begin{abstract}
Prader-Willi syndrome (PWS) is a rare neurodevelopmental genetic disorder associated with a characteristic behavioral phenotype that includes severe hyperphagia and a variety of other behavioral challenges such as temper outbursts and anxiety. These behaviors have a significant and dramatic impact on the daily functioning and quality of life for the person with PWS and their families. To date, effective therapies addressing these behavioral challenges have proven elusive, but several potential treatments are on the horizon. However, a limiting factor for treatment studies in PWS is the lack of consensus in the field regarding how to best define and measure the complex and interrelated behavioral features of this syndrome. The International PWS Clinical Trials Consortium (PWS-CTC, www.pwsctc.org) includes expert PWS scientists, clinicians, and patient advocacy organization representatives focused on facilitating clinical trials in this rare disease. To address the above gap in the field, members of the PWS-CTC "Behavior Outcomes Working Group" sought to develop a unified understanding of the key behavioral features in PWS and build a consensus regarding their definition and description. The primary focus of this paper is to present consensus definitions and descriptions of key phenotypic PWS behaviors including hyperphagia, temper outbursts, anxiety, obsessive-compulsive behaviors, rigidity, and social cognition deficits. Patient vignettes are provided to illustrate the interrelatedness and impact of these behaviors. We also review some available assessment tools as well as new instruments in development which may be useful in measuring these behavioral features in PWS.
\end{abstract}

Keywords: Prader-Willi syndrome, Behavior, Hyperphagia, Temper outbursts, Anxiety, Obsessive-compulsive, Rigidity, Social cognition, Patient vignettes

\footnotetext{
* Correspondence: lauren.roth@fpwr.org; Ischwrtz@uw.edu

${ }^{1}$ Foundation for Prader-Willi Research, Walnut, CA, USA

${ }^{2}$ Department of Rehabilitation Medicine, University of Washington School of Medicine, Seattle, WA, USA

Full list of author information is available at the end of the article
}

(c) The Author(s). 2021 Open Access This article is licensed under a Creative Commons Attribution 4.0 International License, which permits use, sharing, adaptation, distribution and reproduction in any medium or format, as long as you give appropriate credit to the original author(s) and the source, provide a link to the Creative Commons licence, and indicate if changes were made. The images or other third party material in this article are included in the article's Creative Commons licence, unless indicated otherwise in a credit line to the material. If material is not included in the article's Creative Commons licence and your intended use is not permitted by statutory regulation or exceeds the permitted use, you will need to obtain permission directly from the copyright holder. To view a copy of this licence, visit http://creativecommons.org/licenses/by/4.0/ The Creative Commons Public Domain Dedication waiver (http://creativecommons.org/publicdomain/zero/1.0/) applies to the data made available in this article, unless otherwise stated in a credit line to the data. 


\section{Background}

Prader-Willi syndrome (PWS) is a rare genetic neurodevelopmental disorder that occurs in approximately 1 in 15,000 to 30,000 births, caused by a loss of paternally expressed imprinted genes on chromosome 15q11.2q13 [1]. Genetic subtypes of PWS include paternal deletion (del) of the 15q11.2-13 region, which occurs in approximately $65 \%$ of individuals; maternal uniparental disomy (UPD), which occurs in $\sim 30 \%$; and less commonly, an imprinting center defect diagnosed in $3-5 \%$ of cases [2]. PWS affects multiple systems, with clinical features that include hypotonia, growth hormone deficiency, hypogonadotropic hypogonadism, sleep disturbances, reduced pain sensitivity, decreased gastrointestinal motility, and scoliosis. A defining feature of PWS, which is rare among neurodevelopmental disorders, is the significant change in eating behavior over time. Whereas infants with PWS have difficulty feeding and may exhibit failure to thrive, a persistent and unregulated desire to eat (hyperphagia) develops during childhood. Unless access to food is strictly controlled, an overwhelming drive to eat coupled with decreased energy expenditure in individuals with PWS leads to morbid obesity. The physiological basis of hyperphagia in PWS remains unclear, and currently, there are no approved medications that effectively treat hyperphagia or other symptoms commonly seen in the syndrome. However, clinical trials testing the effectiveness of novel agents against hyperphagia and related PWS symptoms are currently underway or recently completed [3-11].

In addition to hyperphagia, other behavioral challenges also prominent in PWS include temper outbursts, anxiety, obsessive-compulsive behaviors, rigidity, and social skills (Table 1) [12-18]. These behaviors may or may not be food related. In addition, as individuals with PWS reach adulthood, they are also at high risk for developing

Table 1 PWS behavioral features definitions

Hyperphagia: intense persistent sensation of hunger accompanied by food preoccupations, an extreme drive to consume food, food-related behavior problems, and a lack of normal satiety

Temper outbursts: highly explosive episodes in which the person with PWS becomes very angry or upset in a way that seems excessive for the situation and also beyond the person's control

Anxiety: excessive worry and tension often related to schedules/ routines, food planning or food security, persons/items of special interest and excessive concerns about the possibility of change

Obsessive compulsive behaviors: repetitive, ritualistic behaviors, collecting and hoarding items, insistence on "sameness," need to know, ask, or tell

Rigidity: ardent inflexibility with certain routines, concepts, or ways of thinking; vigorous resistance to change; black and white thinking

Social cognition: difficulties relating to others, challenges with reciprocal social communication, recognizing others' emotions, empathy and accurate interpretation of social cues. psychiatric illness, including psychosis, anxiety disorders, and major depression [19]. The PWS neuropsychiatric phenotype is further complicated by impaired cognition, including intellectual disability, academic difficulties, and specific deficits in social cognition such as perspective taking and reading social/emotional cues [20-22]. Although some clinical trials and intervention studies are occurring, there are distinct challenges to conducting studies in PWS due to the complex interrelated behavioral features. One limitation for the field is the lack of consensus on how to best define or measure many of the complex behaviors associated with PWS. PWS-CTC "Behavior Outcomes Working Group" includes PWS scientists, clinicians, and patient advocacy organization representatives with expertise in the behavioral aspects of PWS. This group sought to address the lack of consensus definitions and descriptions of PWS-associated behavioral features. Using literature review, clinical patient experience, and parent focus groups, the Working Group developed a unified understanding of the key behavioral features in PWS which is presented here. Developing a consensus understanding of the behavioral manifestations in PWS provides an important foundation upon which treatment studies targeting those behaviors can be developed and pursued.

\section{Hyperphagia in PWS \\ Definition}

Hyperphagia in PWS manifests as an intense persistent sensation of hunger accompanied by food preoccupations, an extreme drive to consume food, food-related behavior problems, and a lack of normal satiety. Hyperphagia falls at the far end of a continuum of overeating behaviors and is considered the most extreme form of overeating [23].

\section{Description}

A complex progression characterizes the development of hyperphagia, a hallmark feature of PWS [24]. Infants with PWS present with hypotonia, excessive sleepiness, decreased activity, poor suck, and may show little interest in food. This stage is typically followed by a period of relatively normal growth and weight gain. Subsequently, young children with PWS begin to gain weight easily and show an increasingly strong interest in food. Most individuals go on to develop hyperphagia marked by a lack of normal satiety and an overwhelming drive to eat. The onset of hyperphagia is variable and can occur in early childhood, but the average age of onset is 8 years old $[24,25]$. This strong drive to consume food is likely underpinned by persistent feelings of hunger with satiation only developing after excessive calorie intake. Even then, satiety does not persist for any length of time compared to a control group without PWS [26]. Individuals 
with PWS can readily consume up to three times the normal caloric intake at a given meal, may hoard food, and may eat discarded food [26, 27]. The lack of normal satiety is notable, as exemplified by reported cases of gastric necrosis or stomach rupture arising from extreme overeating [28, 29]. Hyperphagia is life-long in most individuals with PWS, but eating and food interest can wax and wane over time, especially in response to changes in the environment, such as changes in food security or alterations of the food schedule. In general, no consistent differences in hyperphagia have been found between gender or PWS genetic subtypes [30]. However, one small study found that food-related behaviors were more severe in PWS males with deletion [31]. Overall, the severity of hyperphagia is not necessarily correlated with degree of obesity in PWS; access to food is typically the biggest determinant of weight.

PWS-associated hyperphagia has overlap with several other conditions, including binge eating disorder, addiction, and obsessive-compulsive features (preoccupation with food) [32, 33]. However, it is distinguished from these conditions by its presence in early childhood as well as physiological studies suggesting that the hyperphagia in PWS likely is related to a pathological defect of satiety $[26$, 34-36]. Additionally, a recent study indicated that individuals with PWS display abnormal patterns of neural activity in response to food representations [37].

For families and caregivers, PWS-related hyperphagia is incessant in that once hyperphagia starts, individuals with PWS are constantly in search of food. Thus, for the safety of the person with PWS, restricting access to food and controlling food intake "food security" are paramount and a 24/7 concern for families. Food security may include restricting access to food with locks on refrigerators and pantries, keeping food out of sight and constant supervision, i.e., "eyes on" the person with PWS at all times to ensure they are not seeking/eating food they should not be consuming. This food security must be implemented across all settings, i.e., home, school, work, and social; families must educate all who interact with the person with PWS. Food security also includes schedules and plans for all meals and food consumption. Changes to those plans can lead to significant behavioral challenges for the person with PWS. Families, caregivers, and clinicians have described hyperphagia in PWS as an overwhelming, life-threatening force, which sentences people with PWS to a lifetime of environmental control and restricted lifestyle $[23,38]$. Treating hyperphagia is the highest priority for caregivers [39].

\section{Observable behaviors}

Hyperphagic behaviors in PWS include intense focus on food, which can manifest as excessive talking/asking about food, especially details regarding what and when they will eat, and persistently searching for food. The drive to eat can lead to food sneaking/food theft, eating food left on other people's plates, eating food that is normally considered unacceptable (e.g., food scraps, food in the trash, raw food) or non-food items (e.g., dirt, grass, soap), getting up at night to look for food, taking very large bites of food, and eating very fast [40]. Additional behaviors include becoming agitated or anxious in the presence of food, bargaining for more food, trying to deceive others or lying to obtain food, becoming upset or exhibiting temper outbursts when food is denied, and becoming aggressive to obtain food.

\section{Assessment of the behavior}

The assessment of hyperphagia in the typical population has employed food diaries, visual scales, and test meals in research settings [41]. These methods are considered not useful in PWS due to the individual with PWS's reluctance to report on their food intake related to concerns about "getting in trouble" and worries about dietary repercussions $[42,43]$. Self-report of degree of hunger in individuals with PWS may also be limited by cognitive and communication challenges [44]. In addition, many people with PWS are on calorierestricted diets; thus, food diaries would not accurately reflect their hunger or hyperphagia. Finally, there are ethical problems of test meals [23] in PWS. And given the physiological impairments in satiety mechanisms in PWS, individuals may not fully experience the contrast between hunger and satiety. Thus, PWS patientreported hunger scales are considered to be unreliable in this population.

Given the challenges of self-reporting in this population, the field has focused on the use of observer (i.e., caregiver) reported assessment of hyperphagia in PWS. The most frequently used measure of hyperphagia in PWS is the Hyperphagia Questionnaire for Clinical Trials (HQ-CT) [45]. The HQ-CT is a 9-item scale that assesses the severity of specific hyperphagic behaviors including food seeking and food-related preoccupations by assessing distress and adaptive impairment related to hyperphagia. This instrument is modified from a questionnaire developed specifically to quantify hyperphagia in PWS [42], and adapted for use in clinical trials [45]. This observer-reported outcome measure, which aims to measure more objective food-related behavior, is based on behaviors over the past 2 weeks reported by a caregiver who is familiar with the daily activities of the person with PWS. Beyond self- or observer-reported assessment of hyperphagia in PWS, there is interest in the field for developing assessment tools that employ objective, direct measures of food interest, such as eye gaze or evoked response potentials [46, 47]. 


\section{Temper outbursts in PWS Definition}

Temper outbursts in PWS are defined as highly emotional or explosive episodes in which the person with PWS becomes "very angry or upset in a way that seems excessive for the situation and also beyond the person's control" [48].

\section{Description}

Temper outbursts, sometimes described as emotional outbursts, "tantrums," or "meltdowns," are one of the most common maladaptive behaviors reported by parents of children, adolescents, and adults with PWS $[5,6,37]$, with a significant impact on quality of life, in some instances equal to or greater than hyperphagia. A small study of PWS families showed a high percentage of siblings experienced PTSD symptoms, and families reported lower overall quality of life compared with normative samples [49]. Additionally, for the individual with PWS, temper outbursts often result in reduced opportunities to socialize in the community, limit living options, and undermine employment. Approximately $80 \%$ of individuals with PWS exhibit severe temper outbursts beginning in childhood and persisting throughout adult life [50]. There may be some decrease in frequency of outbursts in adults compared to children with PWS, but adolescents and adults often have outbursts of longer duration than children with PWS [48]. There are no consistent differences in the characteristics of temper outbursts across genders or PWS genetic subtypes [48].

The sequence of behaviors and emotions within temper outbursts in PWS are similar to those seen in typically developing young children, yet the onset begins slightly later in life, and they continue throughout adulthood [48]. These outbursts may be related to "arrested emotional development" in PWS as well to the confluence of hyperphagia, diminished coping skills, poor emotional control/regulation, and limited executive function skills [51-54]. Triggers for temper outbursts in PWS generally fall into the following categories: blocking of a desired goal, a violation of social expectations, perceived injustice, or difficulty dealing with a change in routine $[48,54,55]$. It has been hypothesized that PWS outbursts might be related to hyperphagia. However, Rice et al. [48] found that most parents of young children with PWS reported temper outbursts occurring before the onset of hyperphagia, suggesting outbursts may be developing independent of hyperphagia. One possible mechanism driving the temper outbursts triggered by changes in routine may be a deficit in task-switching ability, a cognitive-related executive function that is an area of particular difficulty in individuals with PWS [56, 57]. Dysregulation of the autonomic nervous system may be another key mechanism underlying temper outbursts in PWS. A small pilot study [58] indicated that stimulation of the vagus nerve decreased temper outbursts for some individuals with PWS, suggesting the role of the autonomic nervous system in this behavioral feature.

\section{Observable behaviors}

Temper outbursts often manifest with the following behaviors: repetitive questioning that may escalate in volume, angry facial expression, increased salivation, talking very loudly, crying, yelling, stomping the feet, slamming doors, kicking, hitting, laying on the ground, and throwing objects/destroying things. Temper outbursts often follow a particular sequence of behaviors starting with emotional behaviors, such as crying and emotional vocalizations. This is rapidly followed by rising anger and more overt behaviors such as verbal and sometimes physical aggression. Early on, it may be possible to distract the individual and avert the full outburst, but there is a point at which the person is unable to bring themselves under control. Temper outbursts may last from minutes to hours before resolving, and there is often a distinct period of "tuning out" or shut down after an outburst and a need for sleep. The sequence may often end with expressions of regret and distress [54].

\section{Assessment of the behavior}

Currently, there are no measures that are validated specifically for the assessment of temper outbursts in PWS; however, several measures have been developed to assess severe behavior challenges in individuals with intellectual disability, which may be applicable to assessing temper outbursts in PWS studies. Among these, the Developmental Behavior Checklist-Monitoring Version (DBC-M) is a caregiver-reported daily diary using items from the Developmental Behavior Checklist [59]. It has been used in a previous clinical trial examining the potential utility of oxytocin for treating behavioral challenges in PWS [53]. Alternatively, the Challenging Behavior Interview has shown utility in a small study assessing the impact of vagus nerve stimulation on temper outbursts in PWS [58]. Finally, the Aberrant Behavior Checklist (ABC-2 [60]; irritability scale) which has been used widely in studies on those with intellectual disability may provide a useful validated measure of temper outbursts in PWS. Bespoke informant diary measures [61] and structured interviews [54] have also been used with some preliminary evidence of validity in PWS.

\section{Anxiety symptoms and behaviors in PWS Definition}

Anxiety is common in PWS and is characterized by excessive worry, and tension often related, but not limited to, schedules/routines, food planning or food security, or 
persons or items of special interest (e.g., teachers, caregivers, pets). Concerns about the possibility of change in these areas are often a trigger for anxiety in PWS.

Anxiety symptoms in PWS can overlap with Generalized Anxiety Disorder (GAD) but also have unique features (e.g., significant worry about food planning/security and items/ people of special interest) that are not fully captured using definitions based on the Diagnostic and Statistical Manual of Mental Disorders (DSM-5) [62].

\section{Description}

Parents and clinicians have observed that individuals with PWS may exhibit significant anxiety in both food and non-food-related situations as well as during times of transition and change of routine [57, 63]. However, some studies do not appear to capture the extent of anxiety in the PWS population $[64,65]$, likely due to challenges of defining and measuring anxiety. Other studies have found moderate to high levels of anxiety in PWS samples $[18,39,40]$. Einfeld et al. [40] found that $43 \%$ of individuals with PWS assessed with the Developmental Behavior Checklist (DBC) had significant levels of anxiety. A recent study, Feighan et al. [18], found that 37\% of participants with PWS were diagnosed with anxiety ( $29 \%$ of adolescents, $43 \%$ of adults), and that anxiety was the most common psychiatric diagnosis in adolescents and adults. Another recent publication examining caregiver preferences for PWS treatment revealed that caregivers rated anxiety as one of their top 2 targets for PWS treatment [39], underscoring the negative impact of anxiety in this population. Finally, a 2018 review of data from the PWS Global Patient Registry [66] found that anxiety symptoms are reported by caregivers to be a significant problem for $48 \%$ of the sample of individuals with PWS ages 10 and above [67].

The prevalence of anxiety symptoms in PWS appears to be similar between males and females but higher in individuals with the UPD genetic subtype of PWS compared to the deletion subtype (73\% vs. $32 \%$ ) according to reports of those caring for individuals with PWS $[67,68]$. Studies assessing age of onset of anxiety in PWS have not been conducted to date; however, clinical observations suggest that many individuals with PWS struggle with anxiety starting around preschool to school age (3-6 years) with peak anxiety symptoms generally occurring during adolescence/early adulthood $[66,69]$.

\section{Observable behaviors}

The Diagnostic Manual-Intellectual Disablity-2 (DMID-2) [70] speaks to the importance of highlighting the behavioral equivalents of anxiety in the assessment of individuals with intellectual disability and limiting reliance on cognitive and more subjective criteria. Although overt behaviors of anxiety may vary in intensity among individuals with PWS, there is a constellation of explicit behaviors that appear to represent anxiety symptoms commonly expressed in individuals with PWS. These include repetitive questioning especially related to schedules, food and people, pacing, loud and/or fast talking, excessive body and hand movements, trembling, and checking behaviors (e.g., checking on people of particular interest and schedules). In addition, individuals with PWS who are more verbal will frequently express many different worries and feelings of being "stressed" or overwhelmed. It should be noted that there is overlap between anxiety behaviors and compulsive behaviors in PWS as described in the section below.

\section{Assessment of the behavior}

There is no validated standard for measuring anxiety in PWS. Previous research has reviewed tools for measuring anxiety in individuals with intellectual disability via selfreport and observer-reported methods [71]. Although some of these measures could be useful in describing anxiety symptoms in PWS, for example, Glasgow Anxiety Scale (GAS-ID) [72] and Anxiety, Depression and Mood Scale (ADAMS) [73], available measures do not appear to fully capture the unique and important manifestations of anxiety in PWS, such as excessive worry about food planning/food security and items/people of special interest. Additionally, given challenges with insight and cognitive difficulties in PWS (e.g., concrete thinking, short term/ working memory difficulties), it can be difficult to accurately assess anxiety in this population especially using selfreport assessment tools. As noted in the DM-ID2, anxiety symptoms in those with intellectual disability can go undetected by others, and individuals with intellectual disability often do not report symptoms of anxiety [70]. Given these reporting difficulties, caregiver/observer-reported assessments of anxiety are recommended. Previous research and clinical trials have employed the (C)YBOCS [4] to assess anxiety in PWS. Although useful, this measure does not appear to fully capture the range of anxiety symptoms in PWS as it focuses almost exclusively on obsessive thoughts and compulsive behaviors. In response to the lack of effective tools to measure the unique anxiety symptoms and behaviors in PWS, a new measure specific to assessing anxiety and distress in PWS is currently being piloted. The Prader-Willi Syndrome Anxiety and Distress Questionnaire (PADQ) is a 20-item caregiver-rated measure that assesses common indices of anxiety and distress in PWS. The PADQ is currently being used as a secondary outcome measure in phase 3 clinical trial in PWS.

\section{Obsessive compulsive behaviors in PWS Definition}

Obsessive-compulsive behaviors (OCB) in PWS are defined as repetitive, ritualistic behaviors that include 
collecting, storing/hoarding items, insistence on routines, and "sameness". Other OCB that are common in PWS are "needing to know, ask or tell" about certain information and distress when this behavior is prevented $[12,13,74-77]$.

\section{Description}

Anxiety in PWS is often discussed within the context of obsessive compulsive behaviors. Previous studies have found relatively high rates of OC-type symptoms in individuals with PWS with $37-58 \%$ having symptoms such as those described above [13]. In a small study, State et al. [76] also found high rates of OC symptoms and concluded that $\mathrm{OC}$ symptoms are prominent in the PWS behavioral phenotype. However, in a longitudinal follow-up of over 250 people with PWS, Dykens and Roof [69] found that only $8 \%$ of their sample met full DSM-5 criteria [62] for diagnosis of obsessive compulsive disorder (OCD). Many of the repetitive rituals participants with PWS engaged in did not meet the standards for performing behaviors related to obsessive thoughts and fears (illness, germs, cleanliness). Ho and Dimitropoulos [78] also found that the obsessions in PWS often did not map onto the typical preoccupations in OCD such as worries about germs, contamination, religion, or others being harmed. One of the most predominant OC behaviors in PWS is repetitive questioning, which may be related to resistance to change. For families, this behavior can be a source of considerable day-to-day frustration, requiring active behavioral management strategies [79]. Clinical observations and several studies suggest that for many individuals with PWS the OC behaviors may bring enjoyment and are soothing in nature, which is different from what is observed in OCD [80-82]. Additionally, the Diagnostic Manual-Intellectual Disability-2 [70] notes that for many individuals with intellectual disability including PWS, obsessive and compulsive behaviors often do not cause clinically significant distress for the person, although aggressive behaviors may occur if the person is prevented from engaging in the behavior, which is different from classic OCD. Differences between PWS-associated OC behaviors and classic OCD are also supported by neuroimaging studies, which found some similarities but also differences in cerebral circuitry activation in PWS compared to classic OCD [83]. Another principal difference is that in DSM-5 OCD definition, the symptoms are "ego-dystonic," that is the person has insight that their thinking is irrational but cannot stop the thought or behavior. In most cases of OC behaviors in individuals with PWS, this insight is not present.

There is limited data on age of onset, frequency, or possible genetic subtype differences in OC symptoms in PWS. Clinical observations and parent reports suggest that many individuals with PWS struggle with OC symptoms starting around age 3 [15]. Higher rates of compulsive behavior have also been reported among 2-3 year olds with PWS compared to typically developing children and young children with Down syndrome [15]. The research on differences in OC symptoms among PWS genetic subtypes is inconclusive, with one study finding that overall OC behaviors were higher in the PWS del subgroup, whereas individuals with PWS UPD tended to have higher rates of $\mathrm{OC}$ behaviors that mimic those commonly observed in autism spectrum disorder (ASD) [84].

\section{Observable behaviors}

Obsessive compulsive behaviors in PWS vary in intensity and scope. However, as described above, there is a constellation of behaviors that are common in this population, including insistence on "sameness" in certain routines and need to know/tell/ask, collecting items of interest/"hoarding," checking behaviors (e.g., checking on collected items of interest), and repetitive rewriting, arranging, and rearranging.

\section{Assessment of the behavior}

Previous research and clinical trials in PWS have employed the Children's Yale Brown Obsessive Compulsive Scale $[4,85]$ to assess OC behaviors. The CY-BOCS is a well-validated frequently used measure of OCD but includes some items that are not pertinent to PWS. Although helpful in describing some of the salient OC symptoms in PWS, the CY-BOCS does not capture the broader manifestations of anxiety in PWS as noted above.

\section{Rigidity in PWS \\ Definition}

Rigidity in PWS is defined as ardent inflexibility with respect to certain routines, concepts, or ways of thinking with vigorous resistance to change. Rigidity can also be characterized as "black \& white thinking" and a resistance to considering information or evidence that might conflict with the rigidly held belief. People with PWS can demonstrate both cognitive and behavioral rigidity.

\section{Description}

Parents and clinical experts report that people with PWS often have rigid thinking styles and behaviors that interfere with daily functioning. Individuals with PWS commonly show a strong resistance to change [17]. This difficulty with change of routine and inflexibility in PWS may be linked to a cognitive deficit in task switching [56, 57]. Task switching requires being able to move from one task to a different task in a timely manner, an area of difficulty for individuals with PWS [56, 86]. 
Studies assessing age of onset of rigidity behaviors in PWS have not been conducted to date. However, clinical observations suggest that many individuals with PWS exhibit behaviors reflecting resistance to change and inflexibility at a young age, generally before starting school. Dykens et al. [87] found that compulsivity and insistence on sameness in routines or events were seen in $76-100 \%$ of the participants with PWS (4-21 years). Little is known about the variation of these behaviors over time, gender, or genetic subtype differences. It is notable that although individuals with PWS have a range of intellectual functioning from moderate intellectual disability (ID) to normal IQ (with some learning challenges), the symptoms of rigidity in PWS are seen across the spectrum of intellectual function in PWS, not just in those with lower (or higher) IQ levels. Clinically, these behaviors have a significant impact on adaptive functioning and are among some of the most difficult behaviors for parents to manage.

\section{Observable behaviors}

Overt behaviors that appear to reflect behavioral rigidity in PWS can include needing to have things done a certain way, including in a particular order, time, or place; difficulty with changes in the schedule or routine; and difficulty transitioning from one activity to another (e.g., brother must always sit in the seat behind the driver, hair must be worn a certain way every day, refusal to take medication if not given the right way). Rigidity can be observed by the person with PWS getting stuck on a certain thought or idea and excessive talking about that topic. Additional characteristics include inflexibility in beliefs and difficulty considering a new perspective or topic even when presented with conflicting information (e.g., only females can be teachers but their teacher is male). Another common observable behavior reflecting rigidity in PWS is significant distress and protest when the rigid behaviors, thoughts, or beliefs are challenged. Additionally, protest and distress behaviors in PWS are often seen when the person with PWS expects something that then does not happen.

\section{Assessment of the behavior}

Commonly used behavior scales (e.g., CY-BOCS, Repetitive Behavior Scale-Revised- RBS-R) do not specifically focus on rigidity. Two domains of the RBS-R do assess needs for sameness and compulsivity in those with autism spectrum disorder (ASD) or ID yet are not specifically tailored to PWS. Some of the rigid behaviors seen in PWS could be captured on the CY-BOCS, but the instrument does not adequately capture the majority of these behaviors and does not focus on cognitive rigidity.

The Montefiore-Einstein Rigidity Scale (MERS-PWS) is currently being developed to capture the above described rigidity characteristic of PWS. The MERSPWS scale measures 3 domains that reflect rigidity: behavioral rigidity, cognitive rigidity, and a protest domain. The MERS-PWS is currently being tested as a secondary outcome measure in a clinical trial examining challenging behaviors in adolescents and young adults with PWS.

\section{Social cognition deficits in PWS \\ Definition}

Individuals with PWS display significant difficulties relating to others, especially peers. The social difficulties seen in PWS are characterized by challenges with reciprocal social communication, recognizing others' emotions, empathy, and accurate interpretation of social cues. Social skills challenges in PWS can overlap with those observed in ASD and are influenced by genetic subtype.

\section{Description}

Individuals with PWS struggle with reciprocal social communication and with recognizing emotions in others, especially negative emotions such as sadness, anger, and fear [88]. Related to this, individuals with PWS have difficulty accurately processing faces [21, 89], interpreting emotional valence in faces, being aware of other's personal space, and show significant developmental delay in "theory of mind" tasks [50, 89-91]. In a recent study, Dykens et al. [88] found that individuals with PWS also have difficulties with accurately perceiving the intentions of others. The above social difficulties could be due to differences in the way individuals with PWS process incoming information, which could impact on social skills. Interestingly, a physiological basis for these deficits is likely, with genetic subtype differences evident in several studies. Individuals with the uniparental disomy [UPD] or imprinting defect [ID] genetic subtypes tend to have more difficulty with social communication and are more likely to be diagnosed with ASD; however, all genetic subtypes of PWS (deletion, UPD, ID) show social challenges [20, 89]. To date, no studies have found significant gender differences in social skills challenges in PWS.

Although there is overlap between the social difficulties seen in PWS and those observed in ASD, the prevalence and nature of ASD in PWS has been the subject of some debate among clinicians and researchers. Estimates of ASD in people with PWS has been as high as $41 \%$ [92]; however, Dykens et al. [87] used multimodal forms of assessment including direct assessments of the person with PWS and an expert clinical panel and found a rate of ASD diagnosis of just $12.3 \%$. The majority of those meeting ASD criteria having the UPD genetic subtype. The authors suggested that high rates of ASD in 
previous studies were based solely on parent-reported screening questionnaires and thus may have overestimated rates of ASD diagnosis. It should be noted, however, that although most of the children with PWS assessed in the Dykens et al. [87] study did not meet criteria for ASD, a large majority had some level of social skill difficulties, especially in the area of reciprocal social interactions.

\section{Observable behaviors}

Observable behaviors that reflect the social skills challenges in PWS can manifest as lack of or minimal reciprocal conversation. The person with PWS typically focuses the conversation on a narrow range of topics they are interested in, with repetitive features in the conversation. People with PWS may tend to play with younger children and struggle more with peers. Difficulty in maintaining personal space (e.g., standing too close) is also common [89]. Social cognitive difficulties have been shown in children as young as 3 years old [93]. Older children and adults with PWS may behave in ways that reflect feelings of being easily slighted; they may be quick to become frustrated or angry and take things personally. People with PWS often have difficulty modifying their social behavior to fit changing situations as they arise. Temper outbursts, difficulties with routine change, and ritualistic and repetitive behaviors, as mentioned above, are common in PWS and present unique challenges in the social arena.

\section{Assessment of the behaviors}

Currently, there are no measures that are specific to assess social skills challenges in PWS. However, some studies exploring social challenges in PWS have employed the Social Responsiveness Scale (SRS) and the Social Competence Inventory [94], which are parentrated inventories [89]. These are well-validated measures to assess social challenges in those with ASD or ID. Other studies have used emotion recognition tasks or vignettes to assess social perceptions. Some of the social challenges seen in PWS are captured by these measures, but they do not adequately assess the breadth of unique social challenges seen in PWS. A combination of parent, clinician, and teacher rating scales, in addition to direct patient measures (e.g., face/emotion tasks), may be necessary to fully capture the nature of social skills challenges in PWS. Tools like the ADOS-2 [95] and other clinician-rated assessments are recommended especially when assessing for ASD. Relying on parent assessments only may give an incomplete picture of the social skills deficits observed in PWS [87].

\section{Overlap of PWS behavioral symptoms and features}

As is apparent from the above descriptions, there can be significant overlap of features among the various behavioral characteristics in PWS (Fig. 1). It may not be feasible to tease apart these features as many individuals with PWS struggle with multiple behavioral challenges simultaneously. As an example, the anxiety, OC behaviors, rigidity, and temper outbursts observed in PWS appear to have significant overlap. One theory is that similar psychological or physiological phenomenon and/or cognitive mechanisms, such as difficulties with task switching or emotion regulation, may underlie these behavioral challenges. However, further research is needed to advance our understanding of the possible mechanisms underlying these key behavioral features in PWS. Overlap of symptoms in mental health and behavioral disorders can be seen in the general population as well, for example, in anxiety and depressive mood disorders [96]. This overlap of symptoms and behaviors across different mental health conditions and features may occur due to universal dimensions of distress or negative affect, as well as to shared genetic and neurobiological aspects of these mental health conditions. This is likely a factor in PWS as well. However, in PWS, it may not be possible to separate out aspects of each of the behavioral challenges unless and until we have effective treatments for that feature. Additionally, one treatment in PWS may address multiple behavioral features seen in the syndrome related to overlapping neurobiological mechanisms and/or genetic factors.

\section{Conclusions and limitations}

The primary aim of this paper is to review the current knowledge base regarding the defining features of the behavioral phenotype in PWS and provide consensus definitions of these behavioral features based on the work of the PWS-CTC Behavior Outcomes Working Group. Developing a unified understanding of the PWS behavioral phenotype is important as interventions and

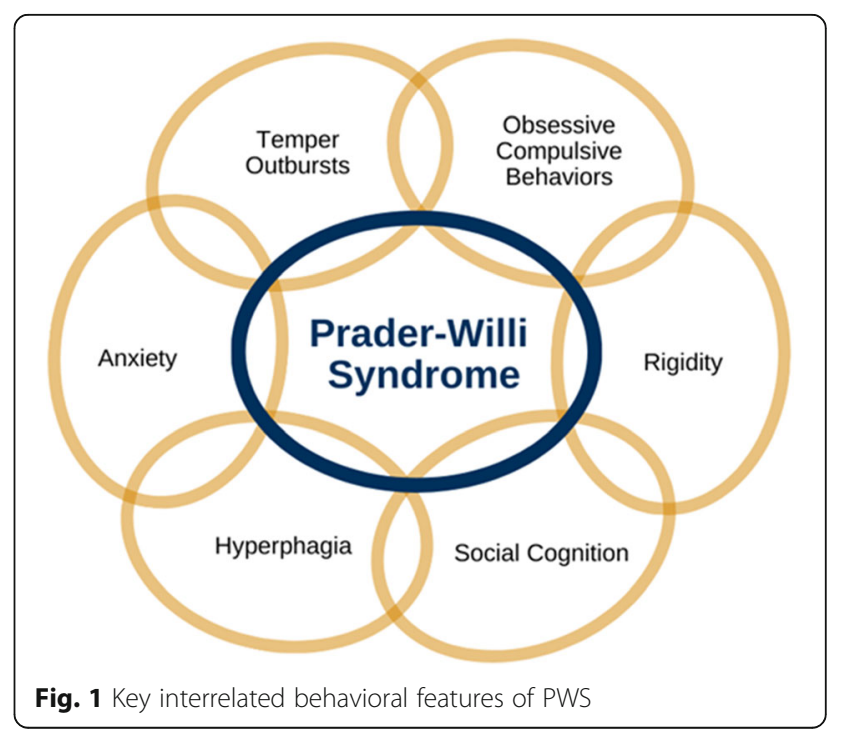


treatments for PWS are moving forward, and the behaviors reviewed in this paper are currently or likely soon to be targets of treatment studies. This paper also highlighted some of the assessment tools that are currently available and under development, which may be useful in measuring these features in PWS. Although the current paper discusses the use of several measurement tools, it was beyond the scope of this paper to provide a complete assessment of available behavioral assessment tools and their potential utility in PWS. This paper represents only an initial foray into this area. Future studies are needed to determine if existing measures for the assessment of behavioral challenges in individuals with intellectual disability can be validated for use in PWS or whether new PWS-specific assessments are needed. Further work on the utility of advancing more appropriate measures for PWS will be an ongoing focus for the PWS-CTC as well as for the field as a whole.

\section{PWS patient vignettes}

The following are PWS patient vignettes to highlight the behavioral features discussed in this paper. These vignettes are not based on any one patient with PWS but rather a combination of different behaviors observed by clinicians with experience working with individuals with PWS.

\section{Feature: hyperphagia}

1. B. is an 18-year-old male with PWS living at home with parents and sister. He admits he is hungry "all the time" but would not admit to taking food around the house or at school. He has taken bolt cutters from the garage to break the locks on the pantry and has also used a screwdriver to take the hinges off locked cabinets to try to get at food. He has convinced classmates that he did not have a lunch after he ate it on the morning bus ride to school. He talks and thinks about food constantly but denies eating food when his mom finds wrappers stuffed in his sneakers. He is clever and fast when it comes to obtaining food; he once stole more than 200 dollars from classmates during a play rehearsal to buy food from a convenience store. Because he is so friendly and social, none of the kids thought he could have done it. They often give him snacks and other food, because he asks "so nicely" even though they know he should not have it.

2. J. is a 10-year-old girl with PWS who was at her brother's baseball game, sitting in the stands with her mother. When her doll fell under the bleachers, her mother let her go down and get it since she felt she could have "eyes on her" the entire time. As she returned from getting her doll, she reached into a backpack that was near the coaching bench and quickly took something out and poured it in her mouth, swallowing hard. Her mother ran to her and asked her what she ate but she put her hands over her mouth and would not talk. Her mother raised her voice in tears asking, "What did you get?" Everyone at the ballpark was looking at them. J never admitted to what she ate but had food around her mouth and hands.

\section{Feature: temper outbursts}

1. $\mathrm{K}$ is a 22-year-old male with PWS living at home with parents and sister. He has aged out of school services and is now waiting for vocational services. He began having temper tantrums at age 8 , and they have gotten progressively worse, with broken furniture, scared family members, and calls to police. For example, K became upset when a sporting event was rained out and he had to leave the field unexpectedly. He became more agitated on the drive home, cursing and asking "why" he had to go home. His parents' explanations about lightning and possible injury or death could not dissuade him from the "unfairness" of the situation. He came home, went to his room and within minutes had broken a lamp, his glasses, and ripped his shirt. $\mathrm{He}$ came out and threatened his mom and tried to hit her with a book. Dad intervened and finally had to sit on his 150-lb son to keep him from injuring himself or others. Police have been called by neighbors and his own parents, but besides taking him to the station or patrol car for a "scared straight moment," they have no answers. He is usually quite tearful and remorseful after these tantrums blow over but admits he cannot control them when they are happening.

2. J is a 10-year-old girl living with PWS. While at school 1 day shortly after recess started, one of the teachers noticed J laying on the ground yelling, swatting, and biting anyone close to her. Then, a loud pitched scream came from her that stopped the playground. J then got up and started running, knocking anyone and anything in her path. She then curled up in a ball on the other side of the field and the teachers told everyone to give J space. She finally calmed and then sat picking handfuls of grass. The vice principal came out to talk to J who at first would not speak. As the principal talked quietly to her, J. calmed down but seemed not to recall the event. When asked how she was feeling, she said, "Fine." She then got up to walk back to her classroom. The principal noted that these episodes happen frequently. 


\section{Feature: obsessive compulsive behaviors}

A is a 16-year-old girl with PWS who lives at home with her parents, attends a local high school, and receives special education services. Her father reports that A collects and hoards hundreds of rubber gloves and spends countless hours sorting, piling, and rolling them into tight balls and then puts them in bins. She does not use the gloves. She does this activity for hours after school, and if her father walks into her room, she must check the sole of his shoes and pockets to make sure that none of her gloves have been inadvertently "picked up". If her parents try to limit this activity or keep her from obtaining more gloves, she becomes hysterical and sometimes aggressive. She even insists on taking them on family trips and recently to her grandfather's funeral.

\section{Feature: anxiety symptoms}

$\mathrm{M}$ is an 11-year-old girl with PWS living with her parents and three siblings. She spends hours a day confirming the daily schedule, asking many questions about who will carry out daily care and academic activities, and needs to check in constantly with mom and a full-time care assistant. She becomes tearful if her mom reminds her that her schedule is the same every day and the same people will be helping her. She asks, "but what if it's not?" What if's rule her life, and $M$ shuts down if caregivers try to discuss this with her. If they persist in this M.'s behaviors escalate to crying and yelling. $M$ asks more than 300 questions a day and does not trust her teacher, aides, and other school staff to help. The school had to call mom every day several times/day because of this. Her anxiety behaviors at school became unmanageable and her mom has chosen to homeschool her now. $\mathrm{M}$ is on more than 3 psychiatric medications, which have helped "take the edge off," but have not reduced her anxiety to allow for increased functioning for M.

\section{Feature: rigidity}

$\mathrm{P}$ is a 23-year-old male living with his parents. He went to a local school and graduated with a regular diploma, fulfilling all state requirements, and he yearns for a "real job". He has been unable to keep employment because of his rigid behaviors. $\mathrm{P}$ feels that tasks should be completed a certain way and is taken to arguing with coworkers and bosses when he feels they are "wrong". He once was fired after arguing with a customer about which dog food is best. P tried unsuccessfully to convince the customer that the food they wanted was not as good for their dog as another brand. The customer tried to be good-natured, but eventually asked for a manager. $\mathrm{P}$ then tried to convince the manager "that no one knows more about dogs than me". He has many strongly held beliefs on everything (from best pizza in Baltimore to worst gorilla exhibit in the USA) and spends a great deal of time trying to convince others that he is right. These beliefs often are based on things he has read and facts that he believes. The preferences and opinions of others do not deter him of his mission that he is right and that others are wrong. His parents are worried that he won't be able to ever maintain employment or social connections because he cannot be dissuaded and that he cannot avoid arguing with and offending others.

\section{Abbreviations \\ PWS: Prader-Willi syndrome; UPD: Uniparental disomy genetic subtype; Del: Deletion genetic subtype; OCD: Obsessive compulsive disorder; OCB: Obsessive compulsive behaviors; ASD: Autism spectrum disorder; ID: Intellectual disability}

\section{Acknowledgements}

Our thanks to Nathalie Kayadjanian for her thoughtful contributions to initial outline and initial draft of the manuscript. We also thank Caroline Vrana-Diaz (FPWR) for her editorial and administrative support. Finally, we thank the members of the PWS-Clinical Trial Consortium for their encouragement to pursue this work.

\section{Authors' contributions}

All authors contributed significantly to developing the conceptual underpinnings of the manuscript and participated in the writing and editing of the manuscript. The authors read and approved the final manuscript.

\section{Funding}

Funding for this project was provided by the PWS-Clinical Trial Consortium (www.pwsctc.org)/Foundation for Prader Willi Research, who provides support in the form of publication costs.

\section{Availability of data and materials}

Not applicable

\section{Declarations}

Ethics approval and consent to participate Not applicable

\section{Consent for publication}

Not applicable

\section{Competing interests}

LS is a consultant to and part of the Research Team at the Foundation for Prader Willi Research

AC-no competing interests

AD-no competing interests

ED-no competing interests

JD-no competing interests

SE-no competing interests

$\mathrm{AH}-$ no competing interests

LR-no competing interests

ER-no competing interest

PS is involved in clinical research funded by Soleno Therapeutics, Inc. \& Millendo Therapeutics, Inc.

TS is an employee of Foundation for Prader Willi Research (FPWR) and

Director of Research Programs at FPWR

BT-no competing interests

$\mathrm{KW}-$ no competing interests

\section{Author details}

${ }^{1}$ Foundation for Prader-Willi Research, Walnut, CA, USA. ${ }^{2}$ Department of Rehabilitation Medicine, University of Washington School of Medicine, Seattle, WA, USA. ${ }^{3}$ Endocrinology and Nutrition Department, Parc Taulí University Hospital, Parc Taulí Research and Innovation Institute, Sabadell, Spain. ${ }^{4}$ Medicine Department, Autonomous University of Barcelona, Sabadell, Spain. ${ }^{5}$ Psychological Sciences, Case Western Reserve University, Cleveland, $\mathrm{OH}$, USA. ${ }^{6}$ Vanderbilt Kennedy Center for Research on Human Development, 
Vanderbilt University, Nashville, TN, USA. ${ }^{7}$ Section of Genetics \& Inherited Metabolic Diseases, Children's Hospital Colorado, University of Colorado Anschutz Medical Campus, Aurora, CO, USA. ${ }^{8}$ Faculty of Medicine and Health, University of Sydney, Camperdown, NSW, Australia. ${ }^{9}$ Trinity College Dublin Trinity Translational Medicine Institute, St. James's Hospital, Dublin 8, Ireland. ${ }^{10}$ Department of Psychiatry, Cambridge Intellectual and Developmental Disabilities Research Group, University of Cambridge, Cambridge, UK. " ${ }^{1}$ Brain and Mind Centre | Faculty of Health Sciences, The University of Sydney, Faculty of Medicine and Health, Camperdown, NSW, Australia. ${ }^{12}$ Department of Psychology and Human Development, Vanderbilt University, Nashville, TN, USA. ${ }^{13}$ Division of Endocrinology and Diabetes, Seattle Children's, University of Washington, Seattle, WA, USA. ${ }^{14}$ Department of Genetics, University of Alabama at Birmingham, Birmingham, AL, USA. ${ }^{15}$ Department of Psychiatry and Behavioral Sciences, Albert Einstein College of Medicine, Bronx, NY, USA. ${ }^{16}$ Centre for Applied Psychology, School of Psychology, University of Birmingham, Edgbaston, Birmingham, UK.

\section{Received: 23 December 2020 Accepted: 9 June 2021}

\section{Published online: 21 June 2021}

\section{References}

1. Driscoll DJ, Miller JL, Schwartz S, Cassidy S. Prader-Willi syndrome. In: Adam M, Ardinger H, Pagon R, editors. GeneReviews; 2017.

2. Butler MG. Prader-Willi syndrome: obesity due to genomic imprinting. Curr Genomics. 2011;12(3):204-15. https://doi.org/10.2174/138920211795677877.

3. Tan Q, Orsso CE, Deehan EC, Triador L, Field CJ, Tun HM, et al. Current and emerging therapies for managing hyperphagia and obesity in Prader-Willi syndrome: a narrative review. Obes Rev. 2020;21(5):1-18. https://doi.org/1 0.1111/obr.12992. Epub 2019 Dec 30.

4. Dykens EM, Miller J, Angulo M, Roof E, Reidy M, Hatoum HT, et al. Intranasal carbetocin reduces hyperphagia in individuals with Prader-Willi syndrome. JCl Insight. 2018;3(12):1-11. https://doi.org/10.1172/jci.insight.98333.

5. Saniona. Co-administration of tesofensine/metoprolol in subjects with Prader-Willi syndrome (PWS). Available from: https://clinicaltrials.gov/ct2/ show/NCT03149445. Cited 2021 Mar 31.

6. Millendo Therapeutics. Effects of livoletide (AZP-531) on food-related behaviors in patients with Prader-Willi syndrome. National Library of Medicine. Available from: https://clinicaltrials.gov/ct2/show/NCT03790865. Cited 2021 Mar 31

7. Levo Therapeutics. Phase 3 study of intranasal carbetocin (LV-101) in patients with Prader-Willi syndrome. National Library of Medicine. Available from: https://www.clinicaltrials.gov/ct2/show/NCT03649477. Cited 2021 Mar 31.

8. Soleno Therapeutics. A study of diazoxide choline in patients with PraderWilli syndrome. National Library of Medicine. Available from: https://www. clinicaltrials.gov/ct2/show/NCT03440814. Cited 2021 Mar 31.

9. Damen L, Grootjen LN, Juriaans AF, Donze SH, Huisman TM, Visser JA, et al. Oxytocin in young children with Prader-Willi syndrome: results of a randomized, double-blind, placebo-controlled, crossover trial investigating 3 months of oxytocin. Clin Endocrinol. 2020;(September):1-12.

10. Allas S, Caixàs A, Poitou C, Coupaye M, Thuilleaux D, Lorenzini F, et al. AZP531, an unacylated ghrelin analog, improves food-related behavior in patients with Prader-Willi syndrome: a randomized placebo-controlled trial. PLoS One. 2018;13(1):1-19.

11. Hollander E, Levine KG, Ferretti CJ, Freeman K, Doernberg E, Desilva N, et al. Intranasal oxytocin versus placebo for hyperphagia and repetitive behaviors in children with Prader-Willi Syndrome: a randomized controlled pilot trial. $J$ Psychiatr Res. 2020:643-51. https://doi.org/10.1016/j.jpsychires.2020.11.006. Epub 2020 Nov 4.

12. Clarke DJ, Boer H, Whittington J, Holland A, Butler J, Webb T. Prader-Willi syndrome, compulsive and ritualistic behaviours: the first population-based survey. Br J Psychiatry. 2002;180(4):358-62. https://doi.org/10.1192/bjp.180.4.358.

13. Dykens EM, Leckman JF, Cassidy SB. Obsessions and compulsions in PraderWilli syndrome. J Child Psychol Psychiatry Allied Discip. 1996;37(8):995-1002. https://doi.org/10.1111/j.1469-7610.1996.tb01496.x.

14. Einfeld S, Tonge B, Turner G, Parmenter T, Smith A. Longitudinal course of behavioural and emotional problems of young persons with Prader-Willi, Fragile X, Williams and Down syndromes. J Intellect Develop Disabil. 1999; 24(4):349-54. https://doi.org/10.1080/13668259900034111.

15. Dimitropoulos A, Ferret ID, Butler MG, Thompson T. Emergence of compulsive behavior and tantrums in children with Prader-Willi syndrome.
Am J Ment Retard. 2001;106(1):39-51. https://doi.org/10.1352/0895-8017(2 001) 106<0039:EOCBAT>2.0.CO;2.

16. Sinnema M, Einfeld SL, Schrander-Stumpel CTRM, Maaskant MA, Boer $H$, Curfs LMG. Behavioral phenotype in adults with Prader-Willi syndrome. Res Dev Disabil. 2011;32(2):604-12. https://doi.org/10.1016/j.ridd.2010.12.014.

17. Haig EL, Woodcock KA. Rigidity in routines and the development of resistance to change in individuals with Prader-Willi syndrome. J Intellect Disabil Res. 2017;61(5):488-500. https://doi.org/10.1111/jir.12368.

18. Feighan SM, Hughes M, Maunder K, Roche E, Gallagher L. A profile of mental health and behaviour in Prader-Willi syndrome. J Intellect Disabil Res. 2020;64(2):158-69. https://doi.org/10.1111/jir.12707.

19. Yang L, Zhan G-d, Ding J-j, Wang H-j, Ma D, Huang G-y, et al. Psychiatric illness and intellectual disability in the Prader-Willi syndrome with different molecular defects - a meta analysis. PLoS One. 2013;8(8). https://doi.org/1 $0.1155 / 2015 / 294127$

20. Whittington J, Holland A. Cognition in people with Prader-Willi syndrome: insights into genetic influences on cognitive and social development. Neurosci Biobehav Rev. 2017;72:153-67. https://doi.org/10.1016/j.neubiorev.2016.09.013.

21. Debladis J, Valette M, Strenilkov K, Mantoulan C, Thuilleaux D, Laurier V, et al. Face processing and exploration of social signals in Prader-Willi syndrome: a genetic signature. Orphanet J Rare Dis. 2019;14(1):262. https:// doi.org/10.1186/s13023-019-1221-3.

22. Strenilkov K, Debladis J, Salles J, Valette M, Mantoulan C, Thuilleaux D, et al. A study of voice and non-voice processing in Prader-Willi syndrome. Orphanet J Rare Dis. 2020;15(1):1-12.

23. Heymsfield SB, Avena NM, Baier L, Brantley P, Bray GA, Burnett LC, et al. Hyperphagia: current concepts and future directions proceedings of the 2nd international conference on hyperphagia. Obesity. 2014;22(S1):S1-17. https://doi.org/10.1002/oby.20646.

24. Miller JL, Lynn CH, Driscoll DC, Goldstone AP, Gold J-A, Kimonis V, et al. Nutritional phases in Prader-Willi syndrome. Am J Med Genet Part A. 2011; 155A(5):1040-9. https://doi.org/10.1002/ajmg.a.33951.

25. Miller JL. Approach to the child with Prader-Willi syndrome. J Clin Endocrinol Metab. 2012;97:3837-44 The Endocrine Society.

26. Holland AJ, Treasure J, Coskeran P, Dallow J, Milton N, Hillhouse E. Measurement of excessive appetite and metabolic changes in Prader-Willi syndrome. Int J Obes. 1993;17(9):527-32.

27. Holland AJ, Treasure J, Coskeran P. Dallow J. Characteristics of the eating disorder in Prader-Willi syndrome: implications for treatment. J Intellect Disabil Res. 1995;39(5):373-81. https://doi.org/10.1111/j.1365-2788.1995.tb00541.x.

28. Wharton RH, Wang T, Graeme-Cook F, Briggs S, Cole RE. Acute idiopathic gastric dilatation with gastric necrosis in individuals with Prader-Willi syndrome. Am J Med Genet. 1997;73(4):437-41. https://doi.org/10.1002/ (SICI) 1096-8628(19971231)73:4<437::AID-AJMG12>3.0.CO;2-S.

29. Butler MG, Manzardo AM, Heinemann J, Loker C, Loker J. Causes of death in Prader-Willi syndrome: Prader-Willi Syndrome Association (USA) 40-year mortality survey. Genet Med. 2016;19(6):635-42. https://doi.org/10.1038/ gim.2016.178.

30. Bueno M, Esteba-Castillo S, Novell R, Giménez-Palop O, Coronas R, Gabau E, et al. Lack of postprandial peak in brain-derived neurotrophic factor in adults with Prader-Willi syndrome. PLoS One. 2016;11(9):e0163468.

31. Gito M, Ihara H, Ogata H, Sayama M, Murakami N, Nagai T, et al. Gender differences in the behavioral symptom severity of Prader-Willi syndrome. Behav Neurol. 2015;2015. https://doi.org/10.1155/2015/294127.

32. Holland AJ, Aman LCS, Whittington JE. Defining mental and behavioural disorders in genetically determined neurodevelopmental syndromes with particular reference to Prader-Willi syndrome. Genes (Basel). 2019;10(12). https://doi.org/10.3390/genes10121025.

33. Salles J, Lacassagne E, Eddiry S, Franchitto N, Salles JP, Tauber M. What can we learn from PWS and SNORD116 genes about the pathophysiology of addictive disorders? Mol Psychiatry. 2021;26(1):51-9. https://doi.org/10.1038/ s41380-020-00917-X.

34. Shapira NA, Lessig MC, He AG, James GA, Driscoll DJ, Liu Y. Satiety dysfunction in Prader-Willi syndrome demonstrated by fMRI. J Neurol Neurosurg Psychiatry. 2005;76(2):260-2. https:/doi.org/10.1136/jnnp.2004.039024.

35. McAllister CJ, Whittington JE, Holland AJ. Development of the eating behaviour in Prader-Willi Syndrome: advances in our understanding. Int J Obes. 2011;35:188-97.

36. Hinton EC, Holland AJ, Gellatly MSN, Soni S, Patterson M, Ghatei MA, et al. Neural representations of hunger and satiety in Prader-Willi syndrome. Int J Obes. 2006;30(2):313-21. https://doi.org/10.1038/s.ijo.0803128. 
37. Blanco-Hinojo L, Pujol J, Esteba-Castillo S, Martínez-Vilavella G, GiménezPalop O, Gabau E, et al. Lack of response to disgusting food in the hypothalamus and related structures in Prader Willi syndrome. Neurolmage Clin. 2019;21:101662. https://doi.org/10.1016/j.nicl.2019.101662.

38. FPWR. PWS perspectives. 2014. Available from: https://www.fpwr.org/pws-pa tient-voices

39. Tsai JH, Scheimann AO, McCandless SE, Strong TV, Bridges JFP. Caregiver priorities for endpoints to evaluate treatments for Prader-Willi syndrome: a best-worst scaling. J Med Econ. 2018;21(12):1230-7. https://doi.org/10.1 080/13696998.2018.1528980.

40. Einfeld SL, Smith A, Durvasula S, Florio T, Tonge BJ. Behavior and emotional disturbance in Prader-Willi syndrome. 1999;82(2):123-7. https://doi.org/10.1 002/(sici)1096-8628(19990115)82:2<123::aid-ajmg4>3.0.co;2-c.

41. De Castro JM. Eating behavior: lessons from the real world of humans. Nutrition. 2000;16(10):800-13. https://doi.org/10.1016/50899-9007(00)00414-7.

42. Dykens EM, Maxwell MA, Pantino E, Kossler R, Roof E. Assessment of hyperphagia in Prader-Willi syndrome. Obesity. 2007;15(7):1816-26. https:// doi.org/10.1038/oby.2007.216.

43. Heal LW, Sigelman CK. Response biases in interviews of individuals with limited mental ability. J Intellect Disabil Res. 1995;39(4):331-40. https://doi. org/10.1111/j.1365-2788.1995.tb00525.x.

44. Irizarry KA, Mager DR, Triador L, Muehlbauer MJ, Haqq AM, Freemark M. Hormonal and metabolic effects of carbohydrate restriction in children with Prader-Willi syndrome. Clin Endocrinol. 2019;90(4):553-61. https://doi.org/1 0.1111/cen.13933.

45. Fehnel SE, Brown TM, Nelson L, Chen A, Kim DD, Roof E, et al. Development of the hyperphagia questionnaire for use in Prader-Willi syndrome clinical trials. Value Health. 2015;18(3):A25. https://doi.org/10.1016/j.jval.2015.03.154.

46. Key AP, Dykens EM. Eye tracking as a marker of hyperphagia in Prader-Willi syndrome. Dev Neuropsychol. 2018;43(2):152-61. https://doi.org/10.1080/ 87565641.2017.1367395.

47. Key AP, Doernberg E. Eye tracking as an objective measure of hyperphagia in children with Prader-Willi syndrome; 2020. p. 1-9.

48. Rice LJ, Woodcock K, Einfeld SL. The characteristics of temper outbursts in Prader-Willi syndrome. Am J Med Genet Part A. 2018;176(11):2292-300. https://doi.org/10.1002/ajmg.a.40480.

49. Mazaheri MM, Rae-Seebach RD, Preston HE, Schmidt M, Kountz-Edwards S, Field $\mathrm{N}$, et al. The impact of Prader-Willi syndrome on the family's quality of life and caregiving, and the unaffected siblings' psychosocial adjustment. J Intellect Disabil Res. 2013;57(9):861-73. https://doi.org/10.1111/j.1365-2788.2 012.01634.x

50. Rice LJ, Gray KM, Howlin P, Taffe J, Tonge BJ, Einfeld SL. The developmental trajectory of disruptive behavior in Down syndrome, fragile $X$ syndrome, Prader-Willi syndrome and Williams syndrome. Am J Med Genet Part C Semin Med Genet. 2015;169(2):182-7. https://doi.org/10.1 002/ajmg.c.31442

51. Lukoshe A, White T, Schmidt MN, van der Lugt A, Hokken-Koelega AC. Divergent structural brain abnormalities between different genetic subtypes of children with Prader-Willi syndrome. J Neurodev Disord. 2013;5(1):31 https://doi.org/10.1186/1866-1955-5-31.

52. Holland AJ, Whittington JE, Butler J, Webb T, Boer H, Clarke D. Behavioral phenotypes associated with specific genetic disorders: evidence from a population-based study of people with Prader-Willi syndrome. Psychol Med. 2003;33(1):141-53. https://doi.org/10.1017/S0033291702006736.

53. Einfeld S, Smith E, Mcgregor IS, Steinbeck K, Taffe J, Rice LJ, et al. A doubleblind randomized controlled trial of oxytocin nasal spray in Prader Willi syndrome. Am J Med Genet Part A. 2014;164(9):2232-9. https://doi.org/10.1 002/ajmg.a.36653.

54. Tunnicliffe P, Woodcock K, Bull L, Oliver C, Penhallow J. Temper outbursts in Prader-Willi syndrome: causes, behavioural and emotional sequence and responses by carers. J Intellect Disabil Res. 2014;58(2):134-50. https://doi. org/10.1111/jir.12010.

55. Cressey H, Oliver C, Crawford H, Waite J. Temper outbursts in Lowe syndrome: characteristics, sequence, environmental context and comparison to Prader-Willi syndrome. J Appl Res Intellect Disabil. 2019;32(5):1216-27. https://doi.org/10.1111/jar.12613.

56. Woodcock KA, Humphreys GW, Oliver C, Hansen PC. Neural correlates of task switching in paternal 15q11-q13 deletion Prader-Willi syndrome. Brain Res. 2010;1363:128-42. https://doi.org/10.1016/j.brainres.2010.09.093.

57. Woodcock KA, Oliver C, Humphreys G. Task-switching deficits and repetitive behaviour in genetic neurodevelopmental disorders: data from children with Prader - Willi syndrome chromosome 15 q11 - q13 deletion and boys with Fragile X syndrome. Cogn Neuropsychol. 2009;26(2):172-94. https://doi. org/10.1080/02643290802685921.

58. Manning KE, Beresford-Webb JA, Aman LCS, Ring HA, Watson PC, Porges SW, et al. Transcutaneous vagus nerve stimulation (t-VNS): a novel effective treatment for temper outbursts in adults with Prader-Willi syndrome indicated by results from a non-blind study. PLoS One. 2019;14(12): e0223750. https://doi.org/10.1371/journal.pone.0223750.

59. Einfeld S, Tonge B. Manual for the developmental behaviour checklist: primary carer version (DBC-P) \& teacher version (DBC-T); 2002.

60. Farmer C, Aman MG. Aberrant Behavior Checklist. In: Encyclopedia of autism spectrum disorders. New York: Springer New York; 2020. p. 1-8.

61. Bull LE, Oliver C, Tunnicliff PL, Woodcock KA. An informant report behavior diary for measuring temper outbursts in an intervention setting. J Dev Phys Disabil. 2015;27(4):489-504. https://doi.org/10.1007/s10882-015-9429-1.

62. American Psychiatric Association. Diagnostic and statistical manual of mental disorders. 5th ed. Washington, DC: American Psychiatric Association; 2014.

63. Holland AJ. Mental health in PWS | IPWSO | Prader Willi syndrome: IPWSO; 2017. Available from: https://www.ipwso.org/mental-health-in-pws. Cited 2020 Oct 14

64. Beardsmore A, Dorman T, Cooper SA, Webb T. Affective psychosis and Prader-Willi syndrome. J Intellect Disabil Res. 1998;42(6):463-71. https://doi. org/10.1046/j.1365-2788.1998.4260463.x

65. Wigren $M$, Hansen S. ADHD symptoms and insistence on sameness in Prader-Willi syndrome. J Intellect Disabil Res. 2005;49(6):449-56. https://doi. org/10.1111/j.1365-2788.2005.00690.x.

66. Foundation for Prader-Willi Research. Global Prader-Willi Syndrome Registry. Available from: https://www.fpwr.org/researchtools/registry. Cited 2020 Oct 14

67. Foundation for Prader-Willi Research. PWS Registry Data: Anxiety In PWS [INFOGRAPHIC]. 2018. Available from: https://www.fpwr.org/blog/pwsregistry-data-anxiety-in-pws-infographic. Cited 2020 Oct 14

68. Dykens EM, Roof E. Behavior in Prader-Willi syndrome: relationship to genetic subtypes and age. J Child Psychol Psychiatry Allied Discip. 2008; 49(9):1001-8. https://doi.org/10.1111/j.1469-7610.2008.01913.x.

69. Dykens EM, Roof E. PWS Vanderbilt Longitudinal Study: PWSA Gathered View; 2016. p. 2. Available from: www.pwsausa.org/wp-content/uploads/201 6/07/webJA2016-GV4

70. Fletcher RJ, Jarrett B, Cooper S-A, editors. Diagnostic manual - intellectual disability (DM-ID-2): a textbook of diagnosis of mental disorders in persons with intellectual disability. Kingston: NADD Press; 2017.

71. Hermans $\mathrm{H}$, van der Pas FH, Evenhuis HM. Instruments assessing anxiety in adults with intellectual disabilities: a systematic review. Res Dev Disabil. 2011;32(3):861-70. https://doi.org/10.1016/j.ridd.2011.01.034.

72. Mindham J, Espie CA. Glasgow Anxiety Scale for people with an Intellectual Disability (GAS-ID): development and psychometric properties of a new measure for use with people with mild intellectual disability. J Intellect Disabil Res. 2003;47(1):22-30. https://doi.org/10.104 6/j.1365-2788.2003.00457.x.

73. Esbensen AJ, Rojahn J, Aman MG, Ruedrich S. Reliability and validity of an assessment instrument for anxiety, depression, and mood among individuals with mental retardation. J Autism Dev Disord. 2003;33(6):617-29. https://doi.org/10.1023/B:JADD.0000005999.27178.55.

74. Feurer D, Dimitropoulos A, Stone WL, Roof E, Butler MG, Thompson T. The latent variable structure of the Compulsive Behaviour Checklist in people with Prader-Willi syndrome. J Intellect Disabil Res. 1998;42(6):472-80. https:// doi.org/10.1046/j.1365-2788.1998.4260472.x.

75. Dimitropoulos A, Blackford J, Walden T, Thompson T. Compulsive behavior in Prader-Willi syndrome: examining severity in early childhood. Res Dev Disabil. 2006;27(2):190-202. https://doi.org/10.1016/j.ridd.2005.01.002.

76. State MW, Dykens EM, Rosner B, Martin A, King BH. Obsessive-compulsive symptoms in Prader-Willi and "Prader-Willi-like" patients. J Am Acad Child Adolesc Psychiatry. 1999;38(3):329-34. https://doi.org/10.1097/00004583-199903000-00021.

77. Novell-Alsina R, Esteba-Castillo S, Caixàs A, Gabau E, Giménez-Palop O, Pujol J, et al. Compulsions in Prader-Willi syndrome: occurrence and severity as a function of genetic subtype. Actas Esp Psiquiatr. 2019;47(3):79-87.

78. Ho A, Dimitropoulos A. Clinical management of behavioral characteristics of Prader-Willi syndrome. Neuropsychiatr Dis Treat. 2010;6:107.

79. Woodcock K, Oliver C, Humphreys G. Associations between repetitive questioning, resistance to change, temper outbursts and anxiety in Prader- 
Willi and fragile-X syndromes. J Intellect Disabil Res. 2009;53(3):265-78. https://doi.org/10.1111/j.1365-2788.2008.01122.x.

80. Vitiello B, Spreat S, Behar D. Obsessive-compulsive disorder in mentally retarded patients. J Nerv Ment Dis. 1989;177(4):232-6. https://doi.org/10.1 097/00005053-198904000-00007.

81. Whitman BY, Thompson T. Neurodevelopmental and neuropsychological aspects of prader-willi syndrome. In: Management of Prader-Willi syndrome. 3rd ed. New York: Springer; 2006. p. 245-71.

82. Dykens EM, Lee E, Roof E. Prader-Willi syndrome and autism spectrum disorders: an evolving story. J Neurodev Disord. 2011;3(3):225-37. https:// doi.org/10.1007/s11689-011-9092-5.

83. Pujol J, Blanco-Hinojo L, Esteba-Castillo S, Caixàs A, Harrison BJ, Bueno M, et al. Anomalous basal ganglia connectivity and obsessive-compulsive behaviour in patients with Prader Willi syndrome. J Psychiatry Neurosci. 2016:41(4):261-71. https://doi.org/10.1503/jpn.140338.

84. Dykens EM, Cassidy SB, King BH. Maladaptive behavior differences in PraderWilli syndrome due to paternal deletion versus maternal uniparental disomy. Am J Ment Retard. 1999;104(1):67-77. https://doi.org/10.1352/08958017(1999)104<0067:MBDIPS>2.0.CO;2.

85. Scahill L, Riddle MA, McSwiggin-Hardin M, Ort SI, King RA, Goodman WK, et al. Children's Yale-Brown Obsessive Compulsive Scale: reliability and validity. J Am Acad Child Adolesc Psychiatry. 1997;36(6):844-52. https://doi. org/10.1097/00004583-199706000-00023.

86. Chevalère J, Postal V, Jauregui J, Copet P, Laurier V, Thuilleaux D. Executive functions and Prader-Willi syndrome: global deficit linked with intellectual level and syndrome-specific associations. Am J Intellect Dev Disabil. 2015; 120(3):215-29. https://doi.org/10.1352/1944-7558-120.3.215.

87. Dykens EM, Roof E, Hunt-Hawkins H, Dankner N, Lee EB, Shivers CM, et al. Diagnoses and characteristics of autism spectrum disorders in children with Prader-Willi syndrome. J Neurodev Disord. 2017;9(1). https://doi.org/10.1186/ s11689-017-9200-2.

88. Dykens EM, Roof E, Hunt-hawkins H, Daniell C, Jurgensmeyer S. Profiles and trajectories of impaired social cognition in people with Prader-Willi syndrome. PLoS One. 2019;14(10):1-19.

89. Dimitropoulos A, Ho A, Feldman B. Social responsiveness and competence in Prader-Willi syndrome: direct comparison to autism spectrum disorder. J Autism Dev Disord. 2013;43(1):103-13. https://doi. org/10.1007/s10803-012-1547-3.

90. Key AP, Jones D, Dykens EM. Social and emotional processing in Prader-Willi syndrome: genetic subtype differences. J Neurodev Disord. 2013;5(1):1-12.

91. Lo ST, Siemensma E, Collin P, Hokken-Koelega A. Impaired theory of mind and symptoms of autism spectrum disorder in children with Prader-Willi syndrome. Res Dev Disabil. 2013;34(9):2764-73. https://doi.org/10.1016/j. ridd.2013.05.024

92. Veltman MWM, Thompson RJ, Roberts SE, Thomas NS, Whittington J, Bolton PF. Prader-Willi syndrome: a study comparing deletion and uniparental disomy cases with reference to autism spectrum disorders. Eur Child Adolesc Psychiatry. 2004;13(1):42-50. https://doi.org/10.1007/ s00787-004-0354-6.

93. Dimitropoulos A, Zyga O, Russ SW. Early social cognitive ability in preschoolers with Prader-Willi syndrome and autism spectrum disorder. J Autism Dev Disord. 2019;49(11):4441-54. https://doi.org/10.1007/s10803-01 9-04152-4

94. Rydell AM, Hagekull B, Bohlin G. Measurement of two social competence aspects in middle childhood. Dev Psychol. 1997;33(5):824-33. https://doi. org/10.1037/0012-1649.33.5.824

95. Lord C, Rutter M, DiLavore P, Risi S, Gotham K, Bishop S. Autism diagnostic observation schedule - 2. 2nd ed. Torrance: Western Psychological Services; 2012

96. Zbozinek TD, Rose RD, Wolitzky-Taylor KB, Sherbourne C, Sullivan G, Stein $M B$, et al. Diagnostic overlap of generalized anxiety disorder and major depressive disorder in a primary care sample. Depress Anxiety. 2012;29(12): 1065-71. https://doi.org/10.1002/da.22026

\section{Publisher's Note}

Springer Nature remains neutral with regard to jurisdictional claims in published maps and institutional affiliations.

\section{Ready to submit your research? Choose BMC and benefit from:}

- fast, convenient online submission

- thorough peer review by experienced researchers in your field

- rapid publication on acceptance

- support for research data, including large and complex data types

- gold Open Access which fosters wider collaboration and increased citations

- maximum visibility for your research: over $100 \mathrm{M}$ website views per year

At BMC, research is always in progress.

Learn more biomedcentral.com/submissions 